\title{
Is semantic interference really automatic?
}

\author{
MICHAEL B. REINER \\ Texas Wesleyan College, Fort Worth, Texas 76105 \\ and \\ FREDERICK J. MORRISON \\ Department of Family Studies, University of Alberta, Edmonton, Alberta T6G 2MB, Canada
}

\begin{abstract}
Interference in picture naming by task-irrelevant words in Stroop-like paradigms has been interpreted as evidence of automatic semantic processing of unattended words. However, this effect may have been due to attentional rather than automatic processing. To test this hypothesis, subjects were instructed either to ignore task-irrelevant words (selective attention) or to attend to them (divided attention). Three separate dependent measures (interference in picture naming, recognition memory, and confidence ratings) provided converging evidence about subjects' attentional strategies. It was predicted that semantic interference would occur in the divided attention condition, but not when subjects attended selectively to the picture and ignored the word. Contrary to predictions, semantic interference occurred in both instruction conditions. Implications for future research on automaticity are discussed.
\end{abstract}

The distinction between automatic and attentional processing is central to current models of information processing and reading (e.g., LaBerge \& Samuels, 1974; Posner \& Snyder, 1975; Shiffrin \& Schneider, 1977). Automatic processes are fast acting, unintentional, and require little processing capacity. Attentional processes are slower, intentional, and require capacity to be activated. Since automatic processes do not draw upon limited attentional capacity, several can be executed in parallel with processes under conscious control and not interfere with their performance. Nevertheless, an automatic process may interfere with attentional processing when its output produces a competing response (Posner \& Snyder, 1975). This is illustrated by the Stroop effect (Stroop, 1935), in which subjects asked to name the ink color of printed words experienced difficulty when the word named a color incongruent with the ink (e.g., the word blue printed in red ink). Although subjects were instructed to ignore the words, interference in colornaming speed indicated they were unable to avoid processing these stimuli. Posner and Snyder (1975) suggested that although semantic analysis of printed words in this case was unintentional, processing of such well learned stimuli was inevitable, reflecting automatic activation.

Recent studies have utilized a paradigm analogous to the Stroop task, in which subjects named pictures to investigate the nature and development of automatic

This research was supported in part by NIMH National Research Service Award 5T32 MH15755 to Michael B. Reiner, NIMH Research Scientist Development Award MH00226, the Clifford E. Lee Foundation, and an NSERC grant to Frederick J. Morrison. The authors thank Judy List, Frank Manis, Kevin Miller, and David Mitchell for comments on an earlier draft. processing of words (Ehri, 1977; Golinkoff \& Rosinski, 1976; Guttentag \& Haith, 1979; Posnansky \& Rayner, 1977; Rayner \& Posnansky, 1978; Rosinski, 1977; Smith \& Magee, 1980; Underwood, 1976, 1977). In the picture-word task, subjects were presented pictures of objects with words printed inside. They were instructed to attend to the pictures and name them aloud, while ignoring the words. Typically task-irrelevant words slowed picture naming speed. The interference was interpreted to result from the disrupting effects of automatic processing of printed words. Further, the degree of interference increased with greater semantic relatedness of picture and word. Greater interference in picture naming by semantically related words was interpreted as evidence of automatic processing of unattended words to a semantic level.

Although semantic interference indicated that the meaning of printed words was activated, previous studies have not ruled out the possibility that "unattended" words actually received some degree of attention. Selective attention instructions do not guarantee that subjects (1) actually ignore task-irrelevant information or (2) prevent to-be-ignored stimuli from attracting attention (Shiffrin \& Schneider, 1977). Examination of previous picture-word studies reveals several reasons to question whether automatic processing underlies semantic interference effects. For example, since stimuli were in view until the subject responded (typically between 500 and $1,500 \mathrm{msec}$ ) picture naming may not have required full attention. Therefore, subjects may have directed attention to naming the pictures and to recognizing the words. Similarly, though subjects were instructed to ignore the words, they may have been suspicious about why words were presented. Subsequently, they may have attended to the words 
in addition to the pictures. Alternatively, since deployment of attention is driven by stimulus input as well as by individual volition (Duncan, 1980; Posner, 1980; Shiffrin \& Schneider, 1977), attention may have been involuntarily directed to the irrelevant stimuli. By inadvertently drawing attention to the words, processing may have been unintentional, although not necessarily automatic. Therefore, to conclude that subjects controlled the deployment of attention and that irrelevant words were unattended, based solely on the fact that subjects were instructed to ignore them, may be unwarranted. Hence, interference in picture naming by task-irrelevant words alone does not constitute sufficient evidence that semantic processing of words was automatic. Other converging measures are needed to provide evidence that subjects ignore the words.

The present study replicated and extended previous research examining semantic interference in picture naming, taking the above comments into account. It was hypothesized that semantic interference in subjects induced to attend selectively would be attenuated or completely eliminated. To test this hypothesis, performance under selective-attention instructions was compared with divided-attention instructions. Experimental conditions were more rigorous than in previous studies and were intended to maximize compliance with the instructions. Stimuli were presented very briefly (i.e., $100 \mathrm{msec}$ ) to make picture naming more difficult. This reduced the likelihood of subjects attending to both the picture and word. Thus, if subjects given selective-attention instructions nevertheless attend to the words, the magnitude of overall interference in their performance should be equivalent to that exhibited by subjects directed to attend to both picture and word (i.e., divided-attention subjects). In addition, an unexpected recognition memory test for the words was given at the end of the experimental session to provide converging evidence that subjects complied with the attention instructions. It was predicted that recognition memory and confidence ratings of subjects directed to attend to the words would be high. In contrast, if subjects instructed to attend selectively actually ignored the words during the experimental task, recognition memory would be less accurate and confidence ratings would be lower.

In answer to the question, "Is semantic interference really automatic?", we anticipated a definitive "no." We predicted that semantic interference would occur in the divided-attention condition, but not when subjects were induced to attend selectively to the pictures and ignore the words. This would indicate that semantic interference in previous picture-word studies probably occurred as a result of attentional, rather than automatic, processing of the words.

\section{METHOD}

\section{Subjects}

Twenty-four undergraduates participated for credit. All had either normal or corrected-to-normal vision, and none had participated in a similar experiment.

\section{Stimuli}

Battig and Montague's (1969) norms were consulted to obtain 10 semantic categories with members represented by concrete, common objects. From each category, a noun was chosen that could be depicted by a simple line drawing. All 10 nouns selected (chair, knife, carrot, train, spider, drum, saw, foot, horse, dress) were within the top six items listed as exemplars of their respective categories, based on production frequencies. Line drawings were made of these items and 10 copies of each were reproduced on index cards measuring $23 \times 15.3 \mathrm{~cm}$. Five copies of each picture were used in the no-distraction condition (pictures without words) and five in the distraction condition (pictures with words), making a total of 50 trials in each condition.

For the no-distraction condition, two random orders of picture presentation were constructed, with the following constraints: Within each successive block of 10 trials, each picture was presented once, and a unique random order for the 10 different pictures was used within each block. These two orders of picture presentation were also used in the distraction condition, but in this case a word was printed within each picture that was either from the same semantic category as the picture or from a different category. Words were printed in black within the pictures using an IBM Selectric typewriter with an Orator typing ball. All letters were in uppercase. The largest pictures subtended a visual angle of at most $3.0 \mathrm{deg}$, and the visual angle of the words was approximately $.55 \mathrm{deg}$ horizontal and $.25 \mathrm{deg}$ vertical.

A 40-word paper-and-pencil recognition memory test was constructed, with 20 old and 20 new items. The 20 old items were further subdivided into 10 same-category words and 10 different-category words. The 20 new items were also subdivided into two groups. Ten were from the same categories as the pictures, and 10 were selected from different categories. The $\mathbf{4 0}$ words were typed in uppercase on a sheet of paper. Words were listed singly in a column, in random order. Next to each word was printed "Yes" and "No," as well as a confidence rating scale ranging from -3 to +3 (zero excluded), with -3 indicating greatest confidence that the item was new and +3 indicating greatest confidence that it was old.

\section{Apparatus}

A Scientific Prototype (Model 320B) three-field tachistoscope was used to present the stimuli. Two of the tachistoscope fields were used, one for the central fixation point and one for the picture stimuli. A Hunter Klockounter (Model 120C) measured each subject's vocal picture-naming time. An ElectroVoice, Inc. (Model 621) microphone was connected to a GrasonStadler (Model 7300A-1) voice-activated relay that stopped the timer when the subject initiated the vocal response.

\section{Procedure}

Subjects were randomly assigned to one of two attention instruction conditions. Half the subjects in each condition were presented the stimuli in one order, and the remaining subjects received the other order. First, subjects were given instructions for the no-distraction (picture-alone) condition. They were informed that there would be a series of trials in which they would briefly see pictures in the tachistoscope, one at a time, without distraction. They were required to name each picture as rapidly and accurately as possible. On each trial, subjects fixated the dot in the center of the visual field when the experimenter said, "Ready." After a "go" signal, a warning interval of $750 \mathrm{msec}$ was followed by stimulus presentation for $100 \mathrm{msec}$. Each subject saw 50 pictures, of which the first block of 10 (warm-up trials) was not included in the data analysis. After responding to all trials in the no-distraction condition, subjects were given a short rest (approximately $3 \mathrm{~min}$ ) before proceeding to the distraction condition. Subjects were informed that they would be seeing pictures again, but that this time words would be printed within them just above central fixation. Subjects in the selectiveattention condition were told that the experimenter was interested in how rapidly they could perform a simple naming task 
when they were being distracted. They were instructed to name the pictures as fast as possible while maintaining accuracy, and they were strongly encouraged to ignore the words that had been included deliberately to distract them. Subjects in the dividedattention condition were told that the experimenter was interested in how well they could perform a simple naming task while trying to attend to other information at the same time. They were instructed both to name the pictures as fast as possible while maintaining accuracy and to attend to the words.

Approximately $1 \mathrm{~min}$ after responding to the 50 trials in the distraction condition, all subjects completed a surprise paperand-pencil recognition memory test. For each of the 40 items on the test, they indicated whether they remembered seeing the word by circling either "Yes" or "No," and rated their degree of confidence in each response.

\section{RESULTS}

An analysis of variance was conducted on each of three dependent measures: interference in picture naming, recognition memory, and confidence ratings. All results reported were significant at or beyond the .05 level.

\section{Interference in Picture Naming}

For each picture-word pair, interference was calculated by subtracting the latency to name the picture in the no-distraction condition from that in the distraction condition. Use of this interference score rather than raw reaction times reduced error variance due to extaneous factors, thereby allowing more direct comparison of interference due to same-category words vs. differentcategory words. No-distraction trials were always presented first, in order to give subjects sufficient practice at picture naming under experimental conditions prior to doing the same task with distraction. For each subject, interference due to same-category picture-word pairs within each block constituted the data from which median interference for the same-category condition per block was calculated. Similarly, interference due to different-category picture-word pairs within each block constituted the data from which median interference for the different-category condition per block was calculated. Eight data points per subject resulted, one median for the same-category condition and one for the different-category condition in each of four blocks. Since errors in picture naming were negligible (less than $2 \%$ of the trials across all subjects), analyses were not conducted on interference for error trials. These trials were excluded from computation of medians per block for each subject.

A 2 (instructions) by 2 (presentation order) by 4 (trial block) by 2 (semantic relationship between picture and word) ANOVA was conducted on mean median interference times, with repeated measures on the third and fourth factor. Order of presentation produced no reliable main effect or interactions. Overall amount of interference varied with attention instructions $[F(1,20)=12.14, \mathrm{MSe}=.092]$. Subjects instructed to ignore the words showed substantially less interference than those told to attend to both stimuli (93 msec vs. $245 \mathrm{msec}$, respectively). Thus, subjects instructed to ignore the words were less affected than subjects directed to attend to both picture and word.

A significant main effect due to the semantic relation between picture and word $[\mathrm{F}(1,20)=8.16, \mathrm{MSe}=.006]$ revealed that naming pictures with same-category words was more interfering than naming pictures with differentcategory words (185 msec vs. $152 \mathrm{msec}$, respectively). Contrary to predictions, there was no interaction between instructions and semantic relation, nor were there higher order interactions $(\mathrm{Fs}<1)$. Thus, increased interference with greater semantic relatedness of picture and word occurred for both selective- and divided-attention subjects.

\section{Recognition Memory}

Hit rate, false alarm rate, and d' score for sameand different-category words were calculated for each subject. Same-category old items were compared to same-category new items in calculating each index, and different-category old items were compared to differentcategory new items. The d'scores were submitted to a 2 (instructions) by 2 (presentation order) by 2 (semantic relation) ANOVA with repeated measures on the last factor.

Order of presentation produced no reliable main effect or interactions. Both main effects of instructions $[F(1,20)=10.63$, MSe $=1.55]$ and semantic relation $[F(1,20)=14.64, \mathrm{MSe}=.45]$ were significant (see Table 1). These effects, however, were qualified by an Instructions by Semantic Relation interaction $[F(1,20)$ $=5.19, \mathrm{MSe}=.45]$. Post hoc Newman-Keuls analysis indicated that memory discrimination of subjects instructed to attend to the words was superior to that of subjects instructed to ignore the words for both sameand different-category words. However, although $d$ ' scores of "attend" subjects were highest for samecategory words, there was no difference in the d'scores of "ignore" subjects as a function of semantic relation. These findings are consistent with the hypothesis that a different attentional strategy was employed by subjects in the selective-vs. divided-attention conditions.

Table 1

Mean Performance on the Recognition Memory Test as a Function of Picture-Word Category for Both Instruction Conditions

Picture-Word Semantic Relationship

Same Category Different Category

\begin{tabular}{llllll} 
& \multicolumn{2}{c}{ Same Category } & & \multicolumn{2}{c}{ Different Category } \\
\cline { 2 - 3 } \cline { 5 - 6 } & I & A & & I & A \\
\hline Hit Rate & .67 & .91 & .44 & .65 \\
False Alarm Rate & .38 & .23 & .23 & .24 \\
d' Value & .98 & 2.59 & .68 & 1.41 \\
\hline
\end{tabular}

Note-I = "ignore" instructions; $A=$ "attend" instructions. 


\section{Confidence Ratings}

Mean confidence ratings were computed for all old and new words on the recognition test. A 2 (instructions) by 2 (presentation order) by 2 (test item type) by 2 (semantic relation) ANOVA with repeated measures on the last two factors produced no reliable main effect or interactions for order of presentation. The main effects of test item type $[F(1,20)=67.51, \mathrm{MSe}=14.70]$ and semantic relation $[\mathrm{F}(1,20)=17.04, \mathrm{MSe}=7.66]$ and their interaction $[\mathrm{F}(1,20)=19.23$, MSe $=2.72]$ were significant. Subjects were more confident they had seen an old, same-category word $($ mean $=1.62)$ than an old, different-category word (mean $=.42$ ), but no difference emerged in confidence ratings when rejecting new words of the two categories (means $=-.88$ and -1.15 , respectively), as indicated by a Newman-Keuls test.

Although there was no main effect of attention instructions $(\mathrm{F}<1)$, there was a reliable Instructions by Test Item Type interaction $[\mathrm{F}(1,20)=10.67$, MSe $=$ 14.70]. Post hoc Newman-Keuls analysis indicated that subjects instructed to attend to the words were more confident they had seen old items $($ mean $=1.62)$ than those instructed to ignore them $($ mean $=.42)$. There was no difference between the groups, however, in their confidence when rejecting new items (means = -1.22 and -.81 , respectively). In addition, mean confidence ratings to old words differed from those to new words for both instruction conditions, although the magnitude of this difference was greater for "attend" subjects. These findings are consistent with the hypothesis that a different attentional strategy was used by subjects across the instruction conditions.

\section{DISCUSSION}

Results provided converging evidence from three different measures that subjects employed different attentional strategies in the selective- and divided-attention conditions. First, those told to ignore task-irrelevant words showed less interference in picture naming than those directed to attend to both stimuli. Second, selective-attention subjects had lower d' scores on the recognition memory test than did subjects told to divide attention. Third, subjects given selective-attention instructions had less confidence in their decision that previously presented test items were old than did subjects given instructions to divide attention between picture and word.

Contrary to predictions, both selective- and divided-attention subjects experienced more interference in picture naming with semantically related than with semantically unrelated words. The present study, therefore, replicated previous findings suggesting that the meaning of task-irrelevant words may be automatically activated (Guttentag \& Haith, 1979; Rosinski, 1977).Under constrained experimental conditions designed to minimize methodological problems of previous studies, even subjects instructed to ignore the words experienced greater interference with same-category picture-word pairs than with differentcategory pairs. Further, the present study extended previous findings by providing independent evidence that subjects were attending as directed.

However, alternative interpretations of the data are possible. Although large differences were found between the instruction conditions, it does not necessarily follow that the selectiveattention subjects paid no attention to the words and processed them automatically. For example, the differences between the two instruction conditions may have reflected a difference in the amount of conscious attention employed; subjects may have allocated relatively more attention to the words in the dividedthan in the selective-attention condition. If so, findings of greater interference and better memory on the part of dividedattention subjects would follow. On the other hand, subjects in the selective-attention condition may have attended to the words to some degree. Therefore, attentional processing may have produced semantic interference in both conditions.

This alternative interpretation also calls into question the role of automatic processing in previously reported picture-word studies, since interference data alone are insufficient to reject this rival hypothesis. An example of this problem has been reported recently by Regan (1981). In that study, task-irrelevant information interfered in a naming task under conditions that precluded automatic processing of those stimuli due to their unfamiliarity. Regan argued that processing of task-irrelevant stimuli may be involuntary under certain conditions, although not necessarily automatic. Future research, therefore, must provide converging evidence to demonstrate that processing is both unintentional and occurs without attention before it can be claimed that processing is automatic. In conclusion, although we anticipated that the answer to our question, "Is semantic interference really automatic?", would be a definitive "no," at best our response is an equivocal "maybe, maybe not."

\section{REFERENCES}

Battig, W. F., \& Montague, W. E. Category norms for verbal items in 56 categories: A replication and extension of the Connecticut category norms. Journal of Experimental Psychology Monograph, 1969, 80,(3, Pt. 2).

Duncan, J. The locus of interference in the perception of simultaneous stimuli. Psychological Review, 1980, 87, 272-300.

EHRI, L. C. Do adjectives and functors interfere as much as nouns in naming pictures? Child Development, 1977, 48, 697-701.

Golinkoff, R. M., \& Rosinski, R. R. Decoding, semantic processing, and reading comprehension skill. Child Development, 1976, 47, 252-258.

GuttentaG, R. E., \& Haith, M. M. A developmental study of automatic word processing in a picture classification task. Child Development, 1979, 50, 894-896.

LABErge, D., \& Samuels, S. J. Toward a theory of automatic processing in reading. Cognitive Psychology, 1974, 6, 293-323.

Posnansky, C. J., \& Rayner, K. Visual-feature and response components in a picture-word interference task with beginning and skilled readers. Journal of Experimental Child Psychology, $1977,24,440-460$.

Posner, M. I. Orienting of attention. Quarterly Journal of Experimental Psychology, 1980, 32, 3-25.

Posner, M. I., \& SNyder, C. R. R. Attention and cognitive control. In R. L. Solso (Ed.), Information processing and cognition: The Loyola Symposium. Hillsdale, N.J: Erlbaum, 1975.

RAYNeR, K., \& Posnansky, C. J. Stages of processing in word identification. Journal of Experimental Psychology: General, 1978, 107, 64-80.

REGAN, J. E., Automaticity and learning: Effects of familiarity on naming letters. Journal of Experimental Psychology: Human Perception and Performance, 1981, 7, 180-195.

Rosinski, R. R. Picture-word interference is semantically based. Child Development, 1977, 48, 643-647.

Shiffrin, R. M., \& Schneider, W. Controlled and automatic human information processing: II. Perceptual learning, automatic attending, and a general theory. Psychological Review, 1977, 84, 127-190.

Smith, M. C., \& Magee, L. E. Tracing the time course of pictureword processing. Journal of Experimental Psychology: General, 1980, 109, 373-392.

Stroop, J. R. Studies of interference in serial verbal reactions. Journal of Experimental Psychology, 1935, 18, 643-662.

(Received for publication June 28, 1982.) 